\title{
EVALUASI PEMBELAJARAN BERBASIS ISLAM KEMUHAMMADIYAHAN SEBAGAI INTERNALISASI PENGUATAN PENDIDIKAN KARAKTER SISWA DI SD MUHAMMADIYAH KOTA MALANG
}

\author{
Delora Jantung Amelia ${ }^{1}$, Kuncahyono ${ }^{2}$ \\ PGSD Universitas Muhammadiyah Malang \\ delorajantung@umm.ac.id ${ }^{1}$, Kuncahyono@umm.ac.id ${ }^{2}$
}

\begin{abstract}
Abstrak
Fakta di lapangan memberikan gambaran bahwa terdapat praktik-praktik pendidikan di saat ini mengalami perubahan. Perubahan yang dimaksud adalah implementasi pembelajaran dengan mengintegrasikan pendidikan karakter. Pendidikan karakter bermuara pada praktik teladan dari setiap stake holder yang ada di sekolah. Stake holder memiliki kontribusi yang besar tidak hanya sebagi praktisi pendidikan, tetapi juga sebagai ujung tombak keberhasilan penerapan pendidikan karakter bagi siswa.

Penelitian ini mendeskripsikan pelaksanaan evaluasi pembelajaran berbasis islam kemuhamadiyahan sebagai upaya penguatan pendidikan karakter di sekolah. Prosedur penelitian ini yaitu dengan cara mengamati kegiatan guru dan siswa saat pembelajaran berlangsung kemudian menganalisis apakah pelaksanan evaluasi dalam pembelajaran berbasis kemuhamamadiyahan mampu menumbuhkan pendidikan karakter siswa.

Sebagian besar kegiatan implementasi kegiatan pembelajran islam kemuahmmadiyahan di SD Muhammadiyah 9 malang, sudah sesuai dengan standar implementasi kurikluum 2013. Pelakanaan implementasi kegiatan pembelajaran islam kemuhammadiyaan memiliki factor pendukung dan penghambat yang mana semua factor penghambat dapat di atasi dengan baik.
\end{abstract}

Kata Kunci : Evaluasi, Pendidikan Karakter

\begin{abstract}
Facts in the field illustrate that there are educational practices currently undergoing change. The intended change is the implementation of learning by integrating character education. This is in the background by the occurrence of a crisis of character and character of the younger generation, especially students in school. Character education leads to the exemplary practice of every stakeholder in the school. Stake holder has a great contribution not only as a practitioner of education, but also as the spearhead of the successful application of character education for students. To realize the implementation of character education in schools, one of them is the application of full day school learning.

This study describes the implementation of evaluation of Islam-based learning later as an effort to strengthen character education in schools. The procedure of this research is by observing the activities of the teacher and students when learning takes place and then analyzing whether the implementation of evaluation in student-based learning is able to foster student character education.

Most of the implementation activities of Islamic learning activities at the Muhammadiyah 9 elementary school in Malang are in accordance with the 2013 curriculum implementation standard. The implementation of Islamic learning activities has a supporting factor and inhibitor which all inhibiting factors can be overcome properly.
\end{abstract}

Keywords: Evaluation, Character Education 


\section{PENDAHULUAN}

Fakta di lapangan memberikan gambaran bahwa terdapat praktik-praktik pendidikan di saat ini mengalami perubahan. Perubahan yang dimaksud adalah implementasi pembelajaran dengan mengintegrasikan pendidikan karakter. Hal ini di latarbelakangi oleh terjadinya krisis karakter dan akhlak generasi muda terutama siswa-siswa di sekolah. Salah satu tujuan pendidikan yaitu tidak hanya membentuk manusia yang cerdas dan terampil, namun diharapkan mampu menghasilkan manusia yang berkarakter. Di Sekolah Dasar (SD) merupakan pendidikan awal untuk mengembangkan diri menjadi lebih baik. Pada masa Sekolah Dasar siswa mulai mengenal teman sebayanya, siswa mulai hidup berkelompok dengan temannya, siswa Sekolah Dasar memiliki rasa ingin tahu yang kuat dan tertarik akan dunia sekitar yang mengelilinginya, mereka suka mengatur dirinya untuk menangani berbagai hal, dan siswa mulai menjadi pribadi yang mandiri. Pada tingkat Sekolah Dasar pendidikan karakter mempunyai andil yang sangat besar untuk menentukan kualitas terciptanya manusia yang memiliki karakter yang cukup baik. Hal itu dikarenakan pada masa Sekolah Dasar adalah masa keemasan yang dijadikan pondasi awal untuk siswa.

Lebih lanjut dewasa ini banyak bermunculan fenomena siswa Sekolah Dasar yang bertidak tidak sesuai dengan karakter seperti suka mencuri, mencontek, berkelahi dengan teman sebaya, kekerasan bahkan sampai dengan berujung tindakan kriminal lainnya. Hal ini dikarenakan mudahnya siswa tingkat Sekolah Dasar mengakses informasi melalui teknologi. Lingkungan tempat tinggal siswa terletak pada lingkungan yang kurang kondusif. Banyaknya para orang tua baik Ayah dan Ibu yang memilih berkarir, sehingga ketika siswa pulang sekolah tinggal sendiri di rumah dan kurang terpantau. Karakter siswa dapat terentuk misalnya melalui kegiatan pembelajaran berbasis nilai Islam kemuhammadiyahan.

Melalui pelaksanaan pembelajaran berbasis kemuhammadiyahan bagi siswa tingkat Sekolah Dasar diharapkan dapat mengakomodadi penguatan pendidikan karakter siswa., sehingga siswa Sekolah Dasar lebih menjadi insan yang beragama dan bertakwa sesuai ajaran islam sehingga siswa mampu menghadapi tantangan jaman yang terus mengalami perubahan. Pembelajaran 
kemuhammadiyahan memberikan pemahaman kepada siswa tentang ideologi, keimanan, dan karakter yang baik berlandaskan AL-Qur'an dan As Sunnah. Pembelajaran berbasis kemuhammadiyahan berorientasi pada setiap kegiatan pembelajaran yang dimulai dari awal siswa mulai masuk ke dalam kelas sampai dengan siswa pulang sekolah.

Berdasarkan paparan di atas, maka peneliti tertarik melakukan penelitian tentang sejauh mana pelaksanaan pembelajaran berbasis islam kemuhammadiyahan sebagai penguatan pendidikan karakter siswa di tingkat Sekolah Dasar serta bagaimana pelaksanaan evaluasi yang dilakssiswaan guru selama ini. Oleh karena itu peneliti melakukan penelitian di SD Muhammadiyah 9 dengan judul "evaluasi pembelajaran berbasis islam kemuhammadiyahan sebagai upaya internalisasi penguatan pendidikan karakter siswa di SD Muhammadiyah 9 Kota Malang”

\section{METODE PENELITIAN}

Pada Penelitian ini menggunakan penelitian deskritif (Ghoni, Junaidi. 2009), yaitu penelitian yang mendeskripsikan kejadian-kejadian. Penelitian ini untuk mendeskripsikan pelaksanaan evaluasi pembelajaran berbasis islam kemuhamadiyahan sebagai upaya penguatan pendidikan karakter di sekolah. Prosedur penelitian ini yaitu dengan cara mengamati kegiatan guru dan siswa saat pembelajaran berlangsung kemudian menganalisis apakah pelaksanan evaluasi dalam pembelajaran berbasis kemuhamamadiyahan mampu menumbuhkan pendidikan karakter siswa.

Desain penelitian ini yaitu deskriptif survei, Desain deskriptif survei tidak digunakan untuk menguji hipotesis dan pengunaan statistik deskriptif (frekuensi, proporsi, mean/rata-rata, median, modus, kuartil, varians, standart deviasi, jumlah, range, nilai maksimun-minimum dsb) untuk mengambarkan apa yang terjadi, lazimnya tidak untuk menerima atau menolak hipotesis.

Pengumpulan data pada penelitian ini dilakukan dengan teknik observasi, wawancara dan dokumentasi. Observasi, dilakukan untuk mengumpulkan data tentang praktik evaluasi pembelajaran yang dilakukan guru di kelas. Angket, Penggunaan angket dalam penelitian ini digunakan untuk mengetahui sejauh mana pelaksanaan evaluasi pembelajaran berbasis 
kemuhammadiyahan yang ditunjukkan oleh indikator-indikator yang telah ditentukan. Wawancara, dilakukan kepada guru yang mempraktikkan evaluasi pembelajaran, kendala yang dihadapi dan solusi terkait kendala dalam implementasi evaluasi pembelajaran di kelas. Dokumentasi, dilakukan untuk mengumpulkan data tentang berbagai peristiwa dalam proses pembelajaran melalui foto, dokumen berupa hasil evaluasi yang selama ini guru-guru buat, dokumen portofolio dan hasil evaluasi pembelajaran.

\section{HASIL DAN PEMBAHASAN}

Kurikulum secara sederhana dapat diartikan sebagai; (1) sejumlah mata pelajaran yang harus di tempuh atau dipeljari siswa sekolah atau dipergurun tinggi untuk memperoleh ijasah tertentu;(2) sejumlah mata pelajaran yang ditawarkan olehlembaga pendidikan atau depertemen (Sepeno dalam Khozin, 2005:151).

Sebagai suatu rencana pembelajaran dalam praktiknya karikulum selalu berubah sesuai perkembangan dan tuntutan masyarakat. Karena itu agar pelaksanaan karikulum menjadi baik dibutuhkan guru atau dosen yang mempunyai tanggung jawab terhadap profesinya. Kurikulum yang baik di butuhkan pula guru atau dosen yang baik, bahkan guru atau dosen yang baik adalah guru dan dosen yang baik.

SD Muhammadiyah 9 Malang menerapkan pembelajaran dengan menggunakan kurikulum 2013 dengan memodifikasi sesuai dengan kebutuhan sekolah. Salah satunya dengan mengintegrasikan pembelajaran keislaman kemuhammadiyahan. Kurikulum dalam pembelajaran di kelas juga diintegrasikan dengan pendidikan karakter. Misalnya saat siswa mau masuk gerbang sekolah, siswa memiliki pasword untuk masuk. Yaitu siswa diwajibkan membaca doa untuk orang tua, kemudian mencium tangan guru. Kemudian setelah masuk koridor disambut oleh bacaan-bacaan alquran. Setelah masuk kemudian siswa bersiap-siap melakukan kegiatan selanjutnya yaitu sholat dhuha berjamaah. Pendidikan karakter yang juga dimunculkan yaitu pada kegiatan IMB (Indahnya mengaji bersama), kemudian siswa juga diajak untuk membiasakan sikat gigi bersama. Hal ini dapat meningkatkan karakter siswa terutama nilai-nilai karakter utama dalam penguatan pendidikan karakter. 
Penanaman pendidikan karakter juga tertuang dalam RPP yang sudah dibuat oleh guru (RPP terlampir). Pembuatan RPP dan kurikulum ini melalui raker atau koordinasi yang dilakukan setiap akhir semester. Kegiatan ini dilakukan bertujuan untuk memperbaharui, memperkuat, dan mengevaluasi pembelajaran dan kegiatan selama satu semester dengan membentuk tim yang meliputi : tim Umum, tim kurikulum, tim ismubah, dan tim kesiswaan.

Pelaksanaan pembelajaran Kemuhammadiyahan seperti yang sudah dijelaskan di awal misalnya dalam pelaksanaan Sholat dhuha secara berjamaah yang dilakukan setiap pukul 07.00-07.30. Hal ini dilakukan semua kelas mulai dari kelas I sampai dengan kelas VI. Untuk kelas I sampai dengan kelas III sholat dhuha dilakukan di kelas masing-masing dengan bimbingan guru kelas, sedangkan untuk kelas IV sampai dengan kelas VI dilakukan di masjid yang didampingi guru agama. Tujuan sholat berjamaan yaitu untuk menanamkan nilainilai karakter misalnya religius dan nilai disiplin. Di dalam pelaksanaan sholat dhuha juga di tanamkan nilai-nilai karakter tanggung jawab seperti kegiatan membaca alquran, hafalan juz amma, dan latihan adzan. Terutama di dalam hafalan Juz Amma merupakan misi SD Muhammadiyah 9 agar lulusannya nanti memiliki kemampuan hafal Juz Amma. Metode hafalan juz Amma dilakukan secara tilawati. Pendampingan kegiatan tilawati di bimbing oleh tim tilawati dari malang raya.

Evaluasi pendidikan AIK perlu dikembangkan pada evaluasi yang bersifat portofolio, yaitu evaluasi yang mencakup proses, hasil dan umpan balik. Evaluasi bukan saja menjadi hak preogatif guru, siswa pun juga berhak menilai apa dan bagaimana proses dan hasil pembelajaran yang selama ini dilaksanakan. Mereka dapat menilai kesungguhan, keterlibatan, kreativitas dan hasil belajarnya. Sedangkan evaluasi basil belajar diarahkan untuk mendapatkan data yang akan dijadikan sebagai bukti mengenai taraf perkembangan atau kemajuan bela jar yang capai oleh peserta didik, setelah mereka mengikuti proses pembelajaran dalam jangka waktu tertentu (Depdiknas, 2002: 2)Kegiatan evaluasi yang dilaksanakan di SD Muhammadiyah 9 malang dilaksanakan secara bervariasi. Hal ini bertujuan untuk mengetahui kemampuan dan keterampilan siswa. Di lihat dari bentuk macam-macam penilaian yang dilakukan oleh guru Islam kemuhammadiyahan yang meliputi penilaian untuk mengukur kemampuan hard 
skill, dan soft skill. Penilaian hard skiil dilakukan dengan tes tulis, tes lisan, dan penugasan. Sedangkan penilaian soft skiil dilakukan dengan pengamatan terhadap kemampuan presentasi, kemampuan bertanya dan menjawab, kerjasama dalam kelompok, serta kedisiplinan untuk hadir di pembelajaran.

Dalam pengembangan potensi siswa selain akademik dikembangkan pula potensi siswa dari segi Non-akademik. Beberapa kegiatan Ekstrakurikuler dibentuk untuk menampung berbagai macam potensi siswa. Berdasarkan data hasil wawancara bersama kaur ismubah SD Muhammadiyah 9 Malang terdapat berbagai kegiatan yang dilakukan oleh siswa terutama dalam segi keagamaan atau keislaman. Adapun dilihat dari aktivitas siswa dari segi keagamaan sebagai berikut. Selain itu SD Muhammadiyah 9 memiliki ciri khas terutama dalam bidang kurikulum pendidikan kemuhammadiyahan. Hal ini menjadi nilai plus jika dibandingkan dengan sekolah lain (sekolah muhammadiyah), khususnya dalam bidang keagamaan/religius. Kadar religiusitas adalah tingkatan sejauh mana pengetahuan, keyakinan, pelaksanaan dan penghayatan seseorang terhadap agamanya. Pembagian aspek-aspek religiusitas meliputi lima dimensi, yaitu dimensi ideologis, dimensi ritual, dimensi pengalaman dan penghayatan beragama, dimensi pengetahuan, serta dimensi konsekuensi.

Kegiatan sholat dhuha berjamaah dilakukan pada hari senin sampai dengan hari kamis. Pada hari jumat, para siswa melaksanakan sholat dhuha secara mandiri dengan bimbingan guru wali kelas. Pada jam 7.30 terdapat kegiatan sholat dhuha berjamaah secara nyaring dengan bergantian kelas. Kelas I-III sholat dhuha jamaah di kelas masing-masing. Kemudian kelas IV sampai dengan kelas VI Sholat dhuha berjamaah di masjid. Tujuan bacaan nyaring ketika sholat dhuha yaitu untuk menyamakan bacaan.

Kegiatan mengaji dengan metode tilawati khususnya untuk kelas I sampai dengan kelas III. Kegiatan mengaji dibimbing oleh guru khusus oleh guru tilawati kota Malang Raya. Guru tilawati memiliki jenjang pendidikan rata-rata S1 dengan memiliki shahadah atau ijazah. Kegiatan mengaji tilawati ini dilakukan secara bergantian antara kelas I sampai kelas III dengan kelas IV sampai dengan kelas VI.

Hafalan alquran dengan target hafalan juz amma. Kegiatan ini dilakukan dengan menggunakan metode tilawati yang didampingi oleh guru khusus tilawati 
kerja sama dari tim tilawati Kota Malang. Pelaksanaan evaluasi dalam kegiatan tilawati. Kegiatan kultum secara bergantian setiap hari. Kegiatan ini dilakukan secara individu bergantian mulai dari kelas I sampai dengan kelas VI. Kegiatan ini bertujuan untuk membentuk nilai-nilai karakter berani, religius, dan tanggung jawab. Siswa memiliki kompetensi tidak hanya dalam baca tulis alquran tetapi juga berbagi ilmu dengan teman lainnyaKhusus hari jumat adalah kegiatan kesiswaan dalam hal ekstrakurikuler. Semua kegiatan didampingi oleh guru pendamping atau guru khusus dalam melatih ekstrakurikuler.

Kegiatan ismubah keputraan dan keputrian. Yaitu kegiatan yang dilakukan oleh semua putra kelas I sampai dengan kelas VI ketika sholat jumat berjamaah, sedangkan para siswa putri di kelas mendapatkan materi tentang keputtrian terutama bagi siswa putri yang beranjak dewasa atau di kelas tinggi. Kegiatan keputrian didampingi oleh guru perempuan, sedangkan kegiatan sholat jumat berjamaah didampingi oleh guru laki-laki.

Kegiatan muatan lokal bahasa Inggris, bahasa Jawa, dan Bahasa Arab. Bahasa arab yang diterapkan di SD Muhammadiyah 9 Malang dilakukan mulai dari kelas rendah kelas I sampai dengan kelas tinggi kelas VI. Kegiatan manasik haji yang dilakukan oleh para siswa sebagai bentuk latihan dan praktik dalam melakukan ibaddah haji. Kegiatan mengembangkan bakat minat, misalnya Hadrah, memasak, kegiatan akademik olimpiade matematika, Secara umum dapat disimpulkan bahwa SD Muhammadiyah 9 Malang menerapkan kegiatan Full day scholl dengan berbagai kegiatan kesiswaan yang ada. Kegiatan yang dilakukan oleh siswa dari kelas I sampai dengan kelas VI berakhir pada pukul 15.30 sore hari. SD Muhammadiyah 9 tidak menerapkan pemberian PR atau tugas rumah, hal ini bertujuan agar siswa bisa bersama-sama dengan orangtuanya dan pembelajaran di sekolah sudah tercukupi. Peran integrasi pendidikan karakter yang muncul sebagai bentuk internalisasi pembiasaan tercermin dari berbagai kegiatan islam kemuhammadiyahan.

Dalam melakasanakan pembelajaran di SD Muhammadiyah 9 Malang terdapat faktor pendukung, yang meliputi: 1)Tersedianya sarana dan prasarana yang sdudah memadai, 2)Peran kepala sekolah dan guru yang menunjang, 3)Peran orang tua selalu yang memberi dukungan terutama dalam kegiatan keagamaan, keislaman. Orang tua lebih suka anaknya mampu untuk mengaji, sholat, dan 
akhlaknya baik, 4)Terdapat toleransi dan silaturahim antara pimpinan cabang muhammadiyah yang ikut memberikan dukungan dan motivasi.

Adapun faktor penghambat yaitu sebagai berikut: 1)Kurangnya kerja sama antara orang tua siswa dalam mengajari anaknya untuk belajar bahasa arab. Hal ini dikarenakan kebanyakan orang tua tidak menguasai kompetensi bahasa arab. Sehingga alternatif selanjutnya dikembalikan lagi ke sekolah untuk dibimbing guru, 2)Kesibukan orang tua siswa sehingga peran orang tua kurang dalam mendampingi anaknya ketika belajar di rumah.

Adapun upaya yang dilakukan guru dan seluruh stake holder dalam mengatasiketerbatasan yaitu: 1)Melakukan koordinasi antar guru dan kepala sekolah agar konsistensi pembelajaran dan pelasanaan evaluasi pembelajaran islam kemuhammadiyahan dapat berjalan lancar, 2)Melaksanakan program secara bertahap dan terus mengevaluasinya, 3)Meningkatkan kemampuan profesionalitas guru melalui pelatihan/seminar, 4)Menghimbau kepada orang tua agar dapat meluangkan waktunya untuk mendampingi anaknya ketika belajar di rumah.

\section{DAFTAR PUSTAKA}

Asis Saefuddin. 2010. Pembelajaran efektif. Bandung: Remaja Rosadarya Offiset

Baharuddin.2010. Pendidikan dan Psikologi Perkembangan Yogyakarta: Aruzz Media.

Depdiknas, 2006. Model Penilaian Kelas Kurikulum Tingkat Satuan Pendidikan (KTSP). Jakarta: Pusat Kurikulum.

Balitbang Depdiknas Fathurrohman, Pupuh \& Sutikno, M. Sobry. 200 . Strategi Balajar Mengajar. Bandung: PT Refika Aditama.

Kemdikbud. 2017. Panduan Penilaian Penguatan Pendidikan Karakter. Jakarta: Pusat Analisis Sinkronisasi Kebijakan Sekretariat Jenderal Kemdikbud.

Khozin.2005. Menggugat pendidikan Muhammadiyah. Cet Ke-I. Penerbitan Universitas Muhammadiyah Malang. Malang.

Khusnul Mufidati. 2013. Full Day School dan Terpadu. Surabaya: Program Studi Pendidikan Islam Program Pascasarjana STAIN Tulungagung.

Permendiknas Nomor 41 Tahun 2007 Tentang Standar Proses untuk Satuan Pendidikan Dasar dan Menengah.

Loukeris, Dionisios,et al. 200. Aspect of the Effectiveness of the Greek Holoimero ('All Day') Primary School. Mediteranean 
Journal ofEducational Studies. Vol.1(2),pp161-174 Diakses dari http://www.um.edu.mt_data/assets/pdf_file/0011/8 $84 \quad / 0 \quad 2$. Diunduh 28 April 2017.

Mohammad Ali dan Mohammad Asrori. 2012. Psikologi Remaja Perkembangan Perserta Didik. Jakarta: PT Bumi Aksara: Jakarta.

Muhibbin Syah. 2004. Psikologi Pendidikan Dengan Pendekatan Terpadu. Bandung : Remaja Rosdakarya.

Sudjana, Nana. 200 . Penilaian Hasil Proses Belajar Mengajar. Bandung: PT Remaja Rosdakarya.

Tim penyusun. 2017. Modul Pelatihan Penguatan Pendidikan Karakter. Jakarta: Pusat Analisis dan Sinkronisasi Kebijakan Sekretariat Jendral Kemdikbud.

Tim Pedoman Pendidikan Al-Islam dan Kemuhammadiyahan Majelis Pendidikan Tinggi PP Muhammadiyah. 2013. Buku Pedoman Pendidikan Al-Islam dan Kemuhammadiyahan Perguruan Tinggi Muhammadiyah. Yogyakarta: Majelis Pendidikan Tinggi Pimpinan Pusat Muhammadiyah.

Wakit, Saipul. 2016. Peran Pendidikan Al-Islam dan Kemuhammadiyahan dalam Meningkatkan Perilaku Keberagamaan Siswa SMA Muhammadiyah 1 Rambipuji Jember. Jurnal Penelitian Ipteks, 1 (1), (online), http://jurnal.unmuhjember.ac.id/index.php/PENELITIAN_IPTEKS/article /view/25 